be looked for, and which therefore may be omitted so as to place the key in the most faverable light, there remain 229 , which lead to families, genera, and groups of species. Now, what characters are employed in these higher categories? Will it be believed that there are only about one-fourth of them which have the slightest allusion to a single structural feature? That seventy-two per cent are altogether given up to the mere matter of the coloring of the wings, rarely including even the distribution of this color in patterns? This is the key which 'A. Reader' pronounces 'excellent;' which subserves no possible use as a guide to relative structure or affinities, but only to discover a name. Its author and 'A. Reader' appear to be afflicted with the same malady. Your reviewer surely made a mistake in calling the key 'fairly good,' for it teaches nothing of the basis of affinities, which it might have been made to do without lessening one whit its value in the special direction sought.

Cambridge, Nov. 26.

Samuer H. Scudder.

\section{Abnormal embryos of trout and salmon.}

In Science observer, vol. v. No. 1, pp. 1-8, S. Garman and S. F. Denton have figured and described a number of abnormal embryos of trout and salmon ; and, under the head of 'Conclusions,' offered " a few conjectures as to the cause and manner of origin of these monstrosities." These conjectures appear to merit a word of comment. Considering it improbable that many of the forms described could arise by fission, an attempt is made to account for their origin at separate points of the surface of the vitellus. It is argued that several spermatozoa must penetrate the egg-membrane at different points. But how can they accomplish this when only one place - the micropyle - has been provided for their entrance? The possibility - not to say probability - of all passing through the micropyle does not appear as one of the conjectures. "Plurality of micropyles' is noted as one of the possibilities, but another hypothesis is urged as the more acceptable; namely, imperfections in the egg-membrane, due to premature extrusion of the eggs. "The finishing touches being put on the outer covering of the egg, the capsule is most likely to prove unfinished if the eggs are taken too soon.... While the capsule in maturity may resist the intrusion of spermatozoa, compelling entrance at the micropyle, in imperfect condition the same capsule would prove a less effective barrier at its pores or elsewhere." All this seems to be disposed of by the well-known fact that the membrane is formed long before the egg is ripe enough to develop. It has been shown that the micropyle is only large enough to admit one spermatozoon at a time, and the impossibility of entering the minute pores has been pointed out more than once.

A strange assumption underlies most of these conjectures : it is the idea that a spermatozoon, without uniting with the female pronucleus, can give rise to an embryo. This point is not directly asserted, but taken for granted, as if it had nothing unnatural or preposterous in it. In the light of what is now known of fecundation, such an idea, to say the least, is wholly untenable. But if this idea is dropped, most of the 'conclusions' are left completely in the air.

That superfetation may be the cause, or one of the causes, which leads to the formation of monsters, has been made very probable by recent observations; but we can hardly regard this as a certainty so long as such men as Professor Kupffer maintain that more than one spermatozoon is required for the normal fertilization of these very fish-eggs.

As to the mode of origin of monsters, - if I may be allowed to express an opinion on the merits of the various theories that have been offered on the subject, - I should say that Lereboullet and Rauber are the only ones who have succeeded in presenting views which are acceptable from an embryological stand-point. Rauber has dealt with the subject in a very thorough manner, and has shown how two or more embryos could arise from the same germ-ring. If two embryos were formed at opposite sides of the ring, their final position would be on opposite sides of the egg, with the heads pointing in the same direction, precisely as represented in the figures of Garman and Denton. We can hardly do better than accept this view until something better is offered to replace it. In supposing themselves limited to the alternatives of, $1^{\circ}$, fission, and, $2^{\circ}$, formation at different germinal centres, these authors have entirely overlooked the more rational mode of interpretation suggested by Lereboullet (Ann. des sc. nat., 1863), and amplified and extended by Professor Rauber (Virchow's Arch. f. pathol. anat. 1xxi. No. 1, and 'Primitivstreifen und neurula der wirbelthiere,' Leipzig, 1877).

Milwaukee, Nov. 25.

\section{The deepest fresh:water lake in America.}

Mr. L. W. Bailey's letter with the above heading (Science, viii p. 412), calling attention to the extraordinary depth of Crater Lake in Oregon, seems to indicate that he regards Lake Temisconata, in the Province of Quebec in Canada, as being an exceptionally deep fresh-water lake. The subjoined figures will illustrate to what extent this idea is sustained by actual soundings : -

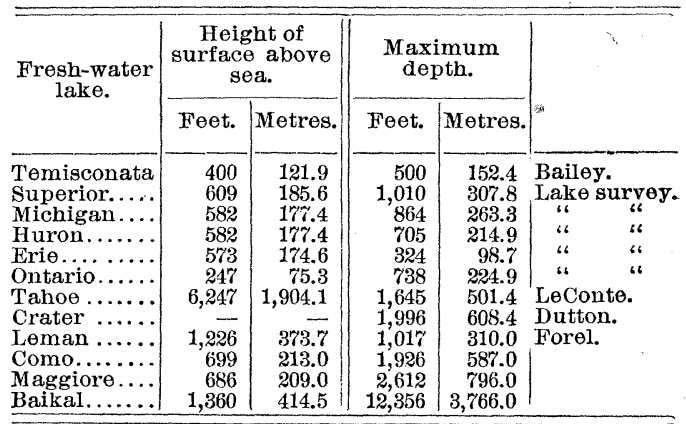

There seem to be unaccountable discrepancies in the depths assigned by different authorities to the chain of lakes lying between Canada and the United States. The table of mean depths given in Johnston's 'Physical atlas' and in Herschel's 'Physical geography' must be erroneous. Some authorities give the maximum depth of Huron as about 1,800 feet. The depth of Lake Baikal appears to be almost incredible (vide Nature, xvii. p. 468).

Berkeley, Cal., Nov. 17. 